\title{
Personality change in older adults with dementia: Occurrence and association with severity of cognitive impairment
}

\author{
Edward Helmes $^{1^{*}}$, Maria C. Norton ${ }^{2}$, Truls Østbye ${ }^{3}$ \\ ${ }^{1}$ Department of Psychology, James Cook University, Townsville, Australia; ${ }^{*}$ Corresponding Author: edward.helmes@jcu.edu.au \\ ${ }^{2}$ Department of Family Consumer and Human Development, Utah State University, Logan, USA \\ ${ }^{3}$ Department of Community and Family Medicine, Duke University, Chapel Hill, USA
}

Received 11 November 2012; revised 12 December 2012; accepted 20 December 2012

\begin{abstract}
Personality change is among criteria for the diagnosis of dementia. We examine first whether personality changes are related to severity of cognitive impairment in a linear or an inverted-U fashion in $\mathbf{1 1 3 2}$ demented older people from the Canadian Study of Health and Aging (CSHA) and 921 unimpaired older people. The proportion with reported change was larger for all measures in the demented group than in the cognitively unimpaired group, and was more consistent with a linear increase in personality change with increasing cognitive impairment than with an inverted-U relationship, as seen in only one variable. In our second (longitudinal) study, we evaluate which aspects of personality change most in dementia; changes in mood and an exaggeration of existing traits were the variables most closely related to the development of dementia.
\end{abstract}

Keywords: Personality Change; Dementia; Affect; Longitudinal Study

\section{INTRODUCTION}

One of the diagnostic criteria for dementia is the presence of personality change, such as in the Diagnostic and Statistical Manual [1]. Obviously, such a criterion can be met by alteration in either one or in many personality characteristics, as long as the magnitude and direction of the change(s) are noticeable to significant others. Such criteria generally take "personality" to be any non-cognitive trait that might be measured by reasonably objective means. With such complexity, it is possible that evaluations of change can be made at different levels, ranging from global ratings of change in any personality trait to quite specific ratings of one particular aspect of per- sonality that is highly salient to the particular observer. In addition, the progression of any changes may be monotonic and linear, with greater change occurring with greater severity of dementia, or progress in a different form and perhaps revert to less dramatic change with increased severity. Here we address some of these issues using data from a large community sample of older Canadians.

The complexities of adult development in later life and corresponding changes in personality features mean that not all relevant research can be reviewed here. A substantial amount of research has concentrated on aspects of personality among healthy, normally aging older adults. Other research has focused on the influence of depression and its relationship to the onset and progression of dementia [2]. Of interest here are the additional studies that have examined the question of personality changes in people with diagnosed dementia. We review each of these areas in turn below, although we exclude the literature on depression and dementia as less relevant to our study.

One of the primary areas of debate and study has been whether there is stability of personality or change into old age. Early evidence [3] suggested that some personality characteristics are more stable than others. Around the same time, Costa and McCrae [4] argued for the stability of all the "Big 5" traits (Neuroticism, Extraversion, Openness, Agreeableness, and Conscientiousness) after age 30, basing their argument upon self-report data from the NEO Personality Inventory. Research by others using different measures provides some support for this position. For example, Conley [5] reported that traits of neuroticism, impulse control and extraversion as assessed by a standard personality scale were stable over a 19 -year interval. Evidence to date is not overwhelmingly supportive of the stability of all personality traits with increasing age as more studies examine the relationship between personality attributes and aging processes. For example, Allemand et al. [6] used the NEO-FFI to test middle- 
aged and older adults a second time after the passage of 4 years. They concluded that the factor structure of the NEO-FFI was invariant across both age groups and time. However, they also found differences across age groups in means, and changes within individuals over time, for all five dimensions of the NEO-FFI. In a subsequent study, Allemand et al. [7] reported similar results and also that some traits tended to change the strength of their association with others, with the exception of Neuroticism. Small et al. [8] reported somewhat similar results with the NEO-PI with adults over 55 years over a 6-year period. Donnellan and Lucas [9] reported data on measures of the Big 5 from two large surveys from Great Britain and Germany to show that Extraversion and Openness tend to decline with increasing age and Agreeableness tends to increase with age.

One of the complexities of the research in this area $[3,10]$ is the question as to how different measurement models of personality characteristics fit with the empirical data on personality in later life [11]. If the stability argument holds and most "normal" personality traits largely remain stable with increasing age, the question remains as to the stability of those dimensions of psychological adjustment as people age. Widiger and Seidlitz [12] review aspects of personality as the term relates to mental health in older adults and note the relative lack of appropriate longitudinal studies of psychopathology in late life. The existing literature largely focuses on the relationship of affect and psychological distress to the development of cognitive decline and dementia.

Among aspects of personality pathology, higher levels of hostility may be associated with increased risk of cognitive decline [13], as may high levels of neuroticism or psychological distress [14,15]. The latter relationship appears to be independent of the presence of overt depression [14]. The importance of such personality pathology changes cannot be underestimated; significant changes in maladaptive personality in an older person can have a major impact on others [16] and can even be associated with survival [15,17-20].

Other changes in personality are associated with the onset of progressive dementia in terms of the known links between brain function and psychological characteristics. For example, personality changes are well known to accompany frontal lobe damage arising from acquired brain injuries and to be more apparent to observers than to those with the injuries [21]; changes in personality are also a feature of frontotemporal dementia [22-24]. The behavioral characteristics associated with frontal lobe damage are rarely investigated in studies of normal personality and dementia, which tend to focus more on Big 5 traits and self-report methods. An example is the report by Wilson et al. [25] of high conscientiousness scores being associated with reduced risk of both Alzheimer's disease and mild cognitive impairment. This report used data from the Religious Orders Study and needs replication using other samples.

One issue related to change in personality in the abnormal aging processes of dementia that is rarely addressed is the nature of the progression of change. Most existing literature implicitly assumes a progressive change in personality with increasing severity of dementia in which more severe or extensive changes in personality occur with more severe dementia [26]. Such changes can be described using linear regression approaches to fit a straight line to the relationship between personality scores and cognitive functioning. On the other hand, a limited amount of evidence indicates that at least some personality traits may become exaggerated and then revert to a more normal state as the dementia becomes more severe. Such a course follows an inverted U-shaped function over time, as noted for certain characteristics by Helson et al. [27]. They evaluated several scales from the California Personality Inventory in two samples from longitudinal studies of personality. They reported some attributes showed linear change over time (e.g., Empathy, Flexibility, Social Presence, and Self-Acceptance), while other attributes showed either an increase from youth to middle age and then a decrease with advancing age (Dominance and Independence) or a decrease in mid-life followed by an increase at later years (Responsibility). Similarly, Crowe et al. [28] tested the hypothesis that moderate extraversion would be associated with lower odds of cognitive impairment compared to being either low or high in extraversion. Similarly, family members may observe early cognitive deterioration and the development of abnormal aspects of personality, with a subsequent return to a baseline level of personality traits as the dementia stabilizes or becomes more severe. This issue has not been explicitly addressed to date in the literature on personality change in people with dementia, which also generally takes place over a shorter period of time than in the above studies. Both the above studies also relied upon self-report measures only. Here we test for the occurrence of such inverted-U patterns (as opposed to the more common pattern of gradual linear change in personality with increasing severity of dementia), using informant reports to provide a different perspective on changes in personality with increasing cognitive impairment. Our data provide information on both global ratings and of changes in more specific characteristics of personality.

A related question is which aspects of personality are more likely to change as a result of the onset of a dementing process. Skoog et al. [29] and Kolanowski and Whall [30] provide reviews of personality change in dementia, noting that premorbid patterns of personality tend to be maintained at least to the stage of moderate 
dementia. In such reports, linear change appears to be assumed. Rubin et al. [31] also noted that personality change increased to being present in over $50 \%$ of cases with severe dementia, with common changes in the characteristics of passivity, agitation, and self-centered actions. Petry et al. [32] also noted an increase in passivity with the development of dementia. These studies suggest that not all changes in personality are exaggerations of pre-morbid characteristics, while Talassi et al. [33] suggest that most personality changes with dementia are into undesirable characteristics. Bozzola et al. [34] reported that personality changes accompanying the progression of the dementia were largely independent of changes in intellectual functioning. In contrast, Jacomb and Jorm [35], using adjective ratings of Big 5 traits, reported the association of some domains of personality with intellectual functions as measured by the IQCODE [36,37]. At the same time, the great majority of these studies relied on self-report measures, which are subject to distortions arising from any reduced capacity for accurate self-report with increasing dementia. As used in this study, observer ratings are less likely to be affected by such factors.

Here we report on two related and complementary studies of personality change using data from two waves of a longitudinal national epidemiological study of older adults in the community. The first (cross-sectional) study relies upon informants' ratings of individuals with and without dementia, supplemented by behavior observations made during the course of the clinical assessment. We evaluate whether any personality measures show evidence of an inverted U-shaped pattern of change with increasing severity of dementia as an alternative to the expectation of linearly increased change in personality with increased severity of dementia. The second (longitudinal) study compares the elderly people who developed dementia over the following five years with those who remained cognitively intact to assess which aspects of personality are most likely to change.

\section{METHOD}

\subsection{Participants}

Data for the cross-sectional analysis are from the first wave of the Canadian Study of Health and Aging (CSHA) $[38,39]$. Participants were included in these analyses if they had taken part in the clinical assessment that included an interview with an informant. A total of 1132 subjects determined to have some form of dementia were contrasted with a group of 921 comparison subjects who had also been clinically evaluated and determined to have no cognitive impairment. The study was approved by the ethics review bodies of the 18 study centers. Information on the diagnostic process and outcomes is given by Graham et al. [40] Individuals were selected to undergo the clinical assessment if they scored below the cut point of 78 on the $3 \mathrm{MS}$ screening test or were selected at random from those who scored above the cut point.

A total of 2305 people underwent the clinical examination of CSHA-2. Of these, 99 who were classified as clearly not cognitively impaired after the initial assessment five years previously (at CSHA-1) developed some form of dementia over the intervening five years. The 2305 people also included 270 people who were found to be cognitively normal at CSHA-1 and were also investigated at the second stage of the CSHA and found to remain cognitively normal. The mean age of the combined group was 77.5 years $(\mathrm{SD}=6.44)$ with a mean of 9.4 years of education $(\mathrm{SD}=4.19)$. The remaining subjects from Study 1 were lost to follow-up, died, refused to participate or developed other forms of cognitive impairment than dementia in the five years between assessments, and were therefore excluded from the longitudinal analyses of those who developed dementia in the intervening 5 years and those who remained cognitively intact on both assessments.

\subsection{Measures}

The CSHA clinical assessment involved a nurse's examination that included a Modified Mini Mental Status Examination (3MS) [41], with a cut point of 78/100, and a structured interview with an informant, neuropsychological assessment by a neuropsychologist, medical history and examination by a physician, and laboratory investigations. The diagnostic process in the CSHA involved a consensus meeting at which the researchers who had assessed that person used the medical history and results of the neuropsychological examination to render a diagnosis [40]. This meeting included the nurse who had completed the informant interview. Computerized diagnostic algorithms were used to confirm consistency with the DSM-III-R [1] and NINCDS-ADRDA [42] diagnostic criteria [40]. Part of this diagnostic process was a consensus rating of the severity of the dementia (none, mild, moderate, and severe) and of the presence of personality change.

The informant interview of the clinical assessment included the CAMDEX [43] and six behavior ratings completed during the neuropsychological assessment to evaluate personality change. Behaviors rated included the presence or absence of 1) inappropriate appearance; 2) reactions to encouragement; 3) agitation; 4) impulsivity; 5) social inappropriateness; and 6) rule violation during the course of the neuropsychological assessment. These were selected as reflecting departures from normative standards of social behavior in the context of a formal assessment with a health care professional. The hypothe- 
sis for the analysis of these ratings is that individuals with dementia will engage in more socially inappropriate behavior in the environment of a formal assessment, compared to control subjects without dementia.

Section $\mathrm{H}$ of the CAMDEX provides an integrative overall rating of the presence or absence of personality change and of seven more specific variables: change in 1) some aspect of overall personality ("Have you noticed any change in his/her personality?"); 2) exaggerated character; 3) changeable mood; 4) angry/irritable (less and more); 5) concern for others (less and more); 6) difficult/embarrassing in public; and 7) stubborn/awkward (less and more). Questions on the seven areas were asked regardless of the response to the initial probe.

\subsection{Analysis}

To assess the shape of the relationship between dementia severity and personality change in the cross-sectional analysis, Cochran-Armitage linear trend tests were used as a first step of analysis. This was followed by fitting linear logistic regression models (one for each element of personality change), assessing the relationship between level of severity of dementia (independent variables) and the element of personality change (binary dependent variable), adjusting for age, gender and years of education in each analysis.

For the longitudinal comparisons, the seven aspects of personality (including the rating of overall personality change from the CAMDEX administered at CSHA-1) were used to contrast the group diagnosed with dementia at CSHA-2 using the criteria of DSM-III-R [1] with those who remained cognitively normal. Initial comparisons were made using the standard test for the comparison of two proportions.

\section{RESULTS}

In the cross-sectional study, seven subjects were missing a rating of dementia severity in the dementia group, as were two subjects from the cognitively intact group, with 253 of the dementia group rated as mild dementia, 441 as moderate, and 421 as severe by the research staff consensus. Table 1 reports the results of cross-tabulations of the diagnosed presence and severity of dementia with the various measures of personality and personality change from the diagnostic conference and CAMDEX. Odds ratios are reported for each level of severity together with the associated $95 \%$ confidence intervals. The odds ratios are for the contrast of each level of severity with the group with no cognitive impairment. It is important to note that for all variables in Table 1, some proportion of individuals without dementia had reports of personality change, ranging from under $4 \%$ for being difficult or embarrassing in public to over $20 \%$ for rat- ings of some personality change. The diagnostic consensus among the CSHA research team members for any type of personality change in those without dementia, however, is lower than the informant global ratings for any change at $6 \%$. Even those with mild dementia had much higher proportions with personality change than those without dementia. The proportion reporting personality change is from two to ten times more common among those with dementia than among those without dementia.

The Cochran-Armitage linear trend tests were highly significant for all measures of personality. Logistic regression analysis revealed that, relative to the cognitively normal group, all three dementia severity groups had a significantly greater proportion affected for all three measures of global personality change: the diagnostic consensus rating, the CAMDEX summary variable, and the seven individual CAMDEX item for any personality change (see Table 1). Nearly all other personality measures also showed monotonic increasing differences from the cognitively intact group with each progressive increase in dementia severity: exaggerated character, changeable mood, more and less concern for others, more and less stubborn, and difficult in public, that all showed clear linear increase in the proportion affected with increasing severity of dementia. For two measures, the prevalence of changes plateaued at the moderate severity level (more angry/irritable, and less angry/irritable). While the test for a linear increasing function was significant $\left(\chi^{2}=186.6,1 \mathrm{df}, \mathrm{p}<0.001\right)$ for the more angry/irritable variable, the proportion of cases showing more anger in the severe dementia group was lower than would be expected given a linearly increasing pattern. Finally, the value for the less angry/irritable variable for the severe dementia group was below that for moderate dementia, demonstrating an inverted-U shape.

Table 2 reports similar information for the absence of observed aberrant behavior from the ratings used in the neuropsychological assessment. In all but one of the behavior ratings, the group with dementia showed significantly lower proportions with conventional social interactions, including elements of personal grooming $(67 \%$ vs. $90 \%, \mathrm{z}=8.25, \mathrm{p}<0.001)$ and generally appropriate social interactions $(83 \%$ vs. $94 \%, \mathrm{z}=4.90, \mathrm{p}<0.001)$. The cognitively intact group reacted better to encouragement $(76 \%$ vs. $42 \%, \mathrm{z}=11.3, \mathrm{p}<0.001)$ and were more likely to remain calm during the assessment session $(87 \%$ vs. $72 \%, z=5.55, p<0.001)$. Individuals with dementia were also less likely to complete all the tests without violating any rules of the tests $(67 \%$ vs. $89 \%, z=$ $8.38, \mathrm{p}<0.001$ ), but this did not appear to be due to impulsivity, which was the same in both groups ( $81 \%$ vs. $85 \%, \mathrm{z}=1.75, \mathrm{~ns})$.

For the longitudinal analyses, Table 3 gives the pro- 
Table 1. Association between dementia severity and occurrence of personality change.

\begin{tabular}{|c|c|c|c|c|c|c|c|c|}
\hline \multicolumn{9}{|c|}{ Severity of Dementia } \\
\hline & None $(\mathrm{N})$ & Mild (N) & Odds Ratio & $\begin{array}{l}\text { Moderate } \\
(\mathrm{N})\end{array}$ & Odds Ratio & $\begin{array}{l}\text { Severe } \\
(\mathrm{N})\end{array}$ & Odds Ratio & $\mathrm{X}^{2}$ Test of \\
\hline & $\%$ & $\%$ & $(95 \% \mathrm{CI})$ & $\%$ & $(95 \% \mathrm{CI})$ & $\%$ & $(95 \% \mathrm{CI})$ & Trend \\
\hline $\begin{array}{c}\text { Diagnostic Consensus on Personality } \\
\text { Change }\end{array}$ & $\begin{array}{c}6.0 \\
(482)\end{array}$ & $\begin{array}{l}63.4 \\
(243)\end{array}$ & $\begin{array}{c}25 \\
(16.7-50)\end{array}$ & $\begin{array}{c}79.9 \\
(427)\end{array}$ & $\begin{array}{c}100 \\
(43.5-111)\end{array}$ & $\begin{array}{l}93.2 \\
(412)\end{array}$ & $\begin{array}{c}200 \\
(111-333)\end{array}$ & $756.5^{* * *}$ \\
\hline CAMDEX Review of Personality Change & $\begin{array}{l}25.9 \\
(911)\end{array}$ & $\begin{array}{l}59.5 \\
(249)\end{array}$ & $\begin{array}{c}4.0 \\
(3.0-5.5)\end{array}$ & $\begin{array}{c}74.2 \\
(438)\end{array}$ & $\begin{array}{c}8.3 \\
(6.3-11.1)\end{array}$ & $\begin{array}{c}85.3 \\
(414)\end{array}$ & $\begin{array}{c}20 \\
(12.5-25)\end{array}$ & $503.7^{* * *}$ \\
\hline Change in Personality & $\begin{array}{l}22.4 \\
(894)\end{array}$ & $\begin{array}{c}51.4 \\
(247)\end{array}$ & $\begin{array}{c}4.0 \\
(3.0-5.5)\end{array}$ & $\begin{array}{c}63.6 \\
(434)\end{array}$ & $\begin{array}{c}6.7 \\
(5.3-9.1)\end{array}$ & $\begin{array}{c}76.1 \\
(410)\end{array}$ & $\begin{array}{c}15.6 \\
(11.0-22.2)\end{array}$ & $395.4^{* * *}$ \\
\hline Exaggerated Character & $\begin{array}{c}8.8 \\
(897)\end{array}$ & $\begin{array}{l}23.5 \\
(247)\end{array}$ & $\begin{array}{c}3.2 \\
(2.2-4.8)\end{array}$ & $\begin{array}{c}36.1 \\
(429)\end{array}$ & $\begin{array}{c}6.3 \\
(4.3-8.3)\end{array}$ & $\begin{array}{c}44.8 \\
(400)\end{array}$ & $\begin{array}{c}11.1 \\
(7.7-12.8)\end{array}$ & $241.3^{* * *}$ \\
\hline Changeable Mood & $\begin{array}{c}15.3 \\
(897)\end{array}$ & $\begin{array}{c}30.2 \\
(248)\end{array}$ & $\begin{array}{c}2.6 \\
(1.9-3.7)\end{array}$ & $\begin{array}{l}48.8 \\
(428)\end{array}$ & $\begin{array}{c}5.9 \\
(4.5-7.7)\end{array}$ & $\begin{array}{c}54.2 \\
(393)\end{array}$ & $\begin{array}{c}7.7 \\
(5.6-11.1)\end{array}$ & $251.9^{* * *}$ \\
\hline Less Angry/Irritable & $\begin{array}{c}8.0 \\
(799)\end{array}$ & $\begin{array}{l}23.7 \\
(196)\end{array}$ & $\begin{array}{c}4.0 \\
(2.6-6.3)\end{array}$ & $\begin{array}{c}36.5 \\
(284)\end{array}$ & $\begin{array}{c}5.0 \\
(3.3-7.1)\end{array}$ & $\begin{array}{c}31.0 \\
(252)\end{array}$ & $\begin{array}{c}5.9 \\
(3.7-9.1)\end{array}$ & $96.5^{* * *}$ \\
\hline More Angry/Irritable & $\begin{array}{c}12.2 \\
(837)\end{array}$ & $\begin{array}{c}31.0 \\
(216)\end{array}$ & $\begin{array}{c}3.1 \\
(2.2-4.5)\end{array}$ & $\begin{array}{c}42.1 \\
(359)\end{array}$ & $\begin{array}{c}5.6 \\
(4.2-7.7)\end{array}$ & $\begin{array}{c}46.1 \\
(323)\end{array}$ & $\begin{array}{c}7.1 \\
(5.0-10)\end{array}$ & $186.6^{* * *}$ \\
\hline Less Concern for Others & $\begin{array}{c}9.0 \\
(865)\end{array}$ & $\begin{array}{l}18.5 \\
(216)\end{array}$ & $\begin{array}{c}2.4 \\
(1.6-3.7)\end{array}$ & $\begin{array}{c}20.5 \\
(308)\end{array}$ & $\begin{array}{c}2.7 \\
(1.9-4.0)\end{array}$ & $\begin{array}{c}34.9 \\
(244)\end{array}$ & $\begin{array}{c}3.8 \\
(2.5-5.9)\end{array}$ & $54.0^{* * *}$ \\
\hline More Concern for Others & $\begin{array}{c}4.5 \\
(824)\end{array}$ & $\begin{array}{l}19.6 \\
(219)\end{array}$ & $\begin{array}{c}5.3 \\
(3.2-8.3)\end{array}$ & $\begin{array}{c}32.9 \\
(365)\end{array}$ & $\begin{array}{c}10 \\
(6.7-14.2)\end{array}$ & $\begin{array}{l}42.7 \\
(316)\end{array}$ & $\begin{array}{c}12.8 \\
(11.1-25)\end{array}$ & $267.5^{* * *}$ \\
\hline Difficult/Embarrassing in Public & $\begin{array}{c}3.6 \\
(892)\end{array}$ & $\begin{array}{c}8.7 \\
(253)\end{array}$ & $\begin{array}{c}2.5 \\
(1.4-4.5)\end{array}$ & $\begin{array}{c}23.0 \\
(413)\end{array}$ & $\begin{array}{c}8.3 \\
(5.3-12.5)\end{array}$ & $\begin{array}{c}30.3 \\
(350)\end{array}$ & $\begin{array}{c}12.5 \\
(8.3-20)\end{array}$ & $194.2^{* * *}$ \\
\hline Less Stubborn/Awkward & $\begin{array}{c}4.5 \\
(821)\end{array}$ & $\begin{array}{c}12.6 \\
(199)\end{array}$ & $\begin{array}{c}3.2 \\
(1.9-5.6)\end{array}$ & $\begin{array}{l}20.0 \\
(285)\end{array}$ & $\begin{array}{c}6.3 \\
(4.0-10)\end{array}$ & $\begin{array}{l}23.9 \\
(230)\end{array}$ & $\begin{array}{c}10 \\
(5.9-16.7)\end{array}$ & $94.5^{* * *}$ \\
\hline More Stubborn/Awkward & $\begin{array}{c}9.4 \\
(865)\end{array}$ & $\begin{array}{l}27.8 \\
(237)\end{array}$ & $\begin{array}{c}3.4 \\
(2.4-5.0)\end{array}$ & $\begin{array}{c}9.5 \\
(377)\end{array}$ & $\begin{array}{c}7.1 \\
(5.0-10)\end{array}$ & $\begin{array}{c}48.5 \\
(340)\end{array}$ & $\begin{array}{c}11.1 \\
(7.7-14.2)\end{array}$ & $251.4^{* * *}$ \\
\hline
\end{tabular}

Note: Multivariate logistic regression (none, i.e. no dementia, is the reference category); Odds ratios are adjusted for age, gender, and years of education. Cochrane-Armitage tests of linear trend all have $1 \mathrm{df} .{ }^{* * *}$ indicates $\mathrm{p}<0.001$.

Table 2. Frequency of behavior rating scale scores related to normative standards of social interactions.

\begin{tabular}{|c|c|c|c|c|}
\hline \multirow{2}{*}{ Domain } & \multicolumn{2}{|c|}{ Cognitively Normal } & \multicolumn{2}{|c|}{ Dementia } \\
\hline & Proportion & $\mathrm{N}$ & Proportion & $\mathrm{N}$ \\
\hline Appearance: Well-Groomed & 90.1 & 788 & 66.7 & $384^{*}$ \\
\hline Reaction to Encouragement: Pride & 75.7 & 787 & 42.4 & $389^{*}$ \\
\hline Agitation: Calm & 86.9 & 572 & 72.1 & $323^{*}$ \\
\hline Impulsivity: Not impulsive & 85.3 & 788 & 81.2 & $389^{*}$ \\
\hline Social Inappropriateness: Absent ${ }^{* *}$ & 93.5 & 786 & 83.3 & $390^{*}$ \\
\hline Absence of Rule Violation: & 89.2 & 785 & 67 & $382^{*}$ \\
\hline
\end{tabular}

NOTE: ${ }^{*} p<0.001 .{ }^{* *}$ Absence of social inappropriateness was lower in the group with dementia, implying greater prevalence of social inappropriateness in this group.

portions of individuals in the two groups with the particular behavior rating. The rating of global personality change from CAMDEX showed substantial differences $(p<0.001)$ between the group that had developed dementia and the group that remained cognitively intact. Smaller but still significant differences were also found for the ratings of an exaggeration of existing character and of changeable moods. All other ratings were not significantly different between the two groups.

\section{DISCUSSION}

The cross-sectional results are consistent with findings from previous studies $[44,45]$ that used self-report mea- 
Table 3. Comparison of relative frequency of aspects of personality between elderly with and without incident dementia between CSHA-1 and CSHA-2.

\begin{tabular}{|c|c|c|c|}
\hline Variable & Dementia $(\mathrm{N})$ & Cognitively Intact $(\mathrm{N})$ & Value of $z$ \\
\hline CAMDEX Review: of Personality Change & $41.4(99)$ & $20.3(266)$ & $4.08^{* * *}$ \\
\hline Exaggerated Character & $25.3(99)$ & $9.3(270)$ & $2.05^{*}$ \\
\hline Changeable Mood & $35.1(97)$ & $13.4(269)$ & $2.34^{*}$ \\
\hline More Irritable/Angry & $25.3(99)$ & $11.5(270)$ & 1.00 \\
\hline Less Irritable/Angry & $14.1(99)$ & $6.70(270)$ & 0.65 \\
\hline More Concerned for Others & $15.3(98)$ & $1.9(269)$ & 0.94 \\
\hline Less Concerned for Others & $7.1(98)$ & $11.5(269)$ & 0.32 \\
\hline Difficulty in Public & $11.1(99)$ & $3.0(266)$ & 0.08 \\
\hline More Stubborn or Awkward & $23.2(99)$ & $8.1(270)$ & 0.99 \\
\hline Less Stubborn or Awkward & $10.1(99)$ & $5.2(270)$ & 1.48 \\
\hline
\end{tabular}

Note: ${ }^{*} \mathrm{p}<0.05,{ }^{* * *} \mathrm{p}<0.001$.

sures in demonstrating changes in personality in people with dementia in comparison to the comparison group of normally aging older adults. This report extends the conclusions to a large, representative community sample. The data also showed that a proportion of those without dementia were evaluated by informants as having undergone personality change and to show less appropriate social interactions with the CSHA research team. This suggests that not all domains of personality remain stable, but it is also possible that other informant effects, such as negative stereotypes of aging, are operating as well. The comparatively lower numbers of such cases in the cognitively intact group suggest that these figures for the ratings may reflect normative levels of change in behaviors related to personality traits among older adults. It is also possible that such personality changes represent very early stages of conditions such as frontotemporal dementia or very mild vascular dementia. Additional followups might detect such cases, although the number of cases with frontotemporal dementia in CSHA was low [38]. It is also notable that the informants were much more willing to acknowledge some aspect of personality change through a global rating on the CAMDEX than were the research team.

There was little support for an inverted U-shaped pattern of personality change with increasing severity of dementia. Only one measure showed clear evidence of an inverted-U distribution, while another showed some signs in showing a plateau. Both of these were ratings of emotional expression: anger and irritability. The limited number of observation points for severity of dementia limits our ability to determine conclusively the actual shape of the apparent non-linear progression that was observed for some other characteristics. These results are also consistent with earlier studies of this issue [27,28]. These studies, however, did not explicitly evaluate the shape of the progression over time and sampled domains of normal personality with normally aging adults. The test of this hypothesis in a large representative community sample provides a more powerful evaluation of whether there is a linear progression of change in personality with the severity of dementia than data from less representative samples from specialty clinics.

A related issue in the assessment of personality change in older adults with dementia is whether the commonly used self-report method is still appropriate. People in the early stages of Alzheimer's disease are often described as lacking insight into the changes in their behavior $[46,47]$. It may therefore be preferable to rely upon informant reports of personality change [45,48,49]. Informant ratings of personality change in people with dementia have included interviews [50] as well as the use of the rater form of the NEO-PI [44]. Retrospective reports of personality can have a normalizing bias [51] but spouses and children generally agree on such ratings [52], despite different amounts of direct contact with the target. At least two informant rating measures have been shown to be reliable by third-party investigators [53].

One limitation of our first (cross sectional) study, shared with studies such as those by Aitken et al. [26], Bozzola et al. [34], Dawson et al. [54], and others, points to an area for future specific study: measurement of "personality change" through assessing the same people at different stages of dementia. In our first study, assessing people at different stages of dementia severity at the same point in time does not assess individual factors well. Longitudinal measurement of both personality traits and dementia status (or severity) permits investigations of 
how change in cognitive status over time is associated with change in personality. Our second study addresses this question.

Our longitudinal results suggest that some readily identifiable changes in personality occur about twice as frequently among individuals who later developed dementia as compared to those who did not develop dementia and instead underwent more benign ageing processes. Such changes comprise more salient expressions of pre-existing personality characteristics, combined with more frequent changes in mood. Miens and Damast [55] compared individuals with Alzheimer's disease and Parkinson's disease and reported greater neuroticism and social isolation in people with Alzheimer's disease, which is consistent with the literature on neuroticism or personal distress and dementia. The present study did not make use of any self-report Big 5 measures of personality, and so more direct comparisons cannot be drawn with the literature on changes in neuroticism as a precursor to dementia, but several of the domains of behavior that were assessed could be associated with increased negative affect. The issue of changes in personality was not one of the primary goals of CSHA, and so there was a limit to the number of characteristics that were assessed. The characteristics chosen were all readily observed aspects of behavior, including those of emotional expression. While any increased irritability noted by the informant may be related to the observed agitation in the assessment session by those with dementia, these behaviors may have other causes than reflecting an underlying personality trait such as neuroticism.

One salient aspect of this study is its use of observers (family members and researchers) to report on aspects of personality rather than the more common self-report measures that can be affected by self-presentation biases. The observers noted a rather high degree of personality change in those assessed not to be cognitively impaired, with a notably higher level of personality change in those diagnosed with dementia. At the same time, we do not suggest that personality change is sufficiently specific to dementia such that increases or decreases in the strength of personality traits could be used as a reliable reflection of the onset of dementia.

A limitation of the study is the use of single items from CAMDEX as opposed to longer instruments that are likely to be more reliable, and in some cases, to assess a broader range of content. However, the use of CAMDEX as a source of information about personality is more likely to result in the assessment of characteristics directly associated with changes accompanying dementia than if generic measures of personality were used because the selection of questions in CAMDEX is largely based upon clinical experience with cases of dementia. It is notable that linear progression is evident for virtually all characteristics in Table $\mathbf{1}$, whereas studies using measures of the Big 5 set of traits often show no effect $[35,48,49,56]$. It may well be that more systematic investigation of other characteristics may show inverted$\mathrm{U}$ functions for other domains than anger/irritability.

A further limitation is the multiple possible explanations for changes in personality and interpersonal behaviors in people with dementia. While the loss of neurons and shrinkage in cortical gray matter in dementia can lead to some similar personality changes to those observed in traumatic brain injuries, particularly those to the frontal cortex, alternative explanations exist. For example, an inability to interpret correctly cues to expressions of emotions and moods in others could lead to being perceived differently by others in turn.

However, our results also suggest that using informants instead of relying solely upon self-reports can lead to additional insights into the changes in behavior associated with the development of dementia. Our results showed that a proportion of individuals who remained cognitively intact still showed some change in personality that was noticed by informants or by health care professionals who were not as highly familiar with the person but who interacted closely with them. Changes in personality were much more evident in the group that had dementia than in the cognitively intact comparison group and covered a broad range of characteristics. Further work at both the theoretical and empirical levels is needed to differentiate changes in personality associated with normal aging from those associated with the early stages of dementia, and whether any such changes are more or less likely to be associated with types of dementia.

The study has implications for families with a history of dementia in older generations. Smith-Gamble et al. [56] reported a similar likelihood across cultures of personality change predicting the development of dementia. Most research on personality change in older adults, including the results presented here, suggests that personality remains stable in the majority of normally aging older adults. Therefore, evidence of changes in personality and exaggeration of characteristic personality factors in older adults may warrant referral to specialists for further evaluation as the changes may be indicative of development of some form of dementia. This study also has the benefit of using data from a large national representative survey that increases the generalizability of the results.

Our study also was able to show the changes that emerge in people who are in the early stages of dementia. These changes were largely in the form of changes in mood and in more extreme expressions of pre-existing personality characteristics. This provides a different perspective on the issue of personality changes than is found in studies that compare normal controls to people with 
dementia of varying degrees of severity, or that are only conducted at one point in time.

This study did not explore the issue of personality change in the group that CSHA diagnosed as CIND. This heterogeneous group included some people with longstanding cognitive impairment as well as those likely to be in the early stages of some form of dementia, i.e., somewhere between the subjects with dementia and the comparison subjects in our study. Whether more refined diagnoses of subtypes of MCI, such as those with changes only on tests of episodic memory, would be associated with different personality factors than identified here is a matter for additional study. Future research should also examine personality characteristics using longer, more reliable measures and those that encompass a broader range of characteristics than the popular Big Five. Such research should also incorporate measures from other sources, including observers from daily interactions and from specific encounters.

\section{CONCLUSION}

Our study relied upon observer reports of personality change rather than the more common self-reports. While some personality change was observed in the cognitively intact group, changes were much more prominent in the group diagnosed with dementia. Early in the development of dementia, the most commonly observed changes are in mood and the exaggeration of existing personality characteristics. Changes were mostly linear, with only two measures showing evidence of non-linear changes with the passage of time. Observer reports and observations of older adults in structured settings can provide valuable information about personality attributes and their alterations with the development of dementia.

\section{ACKNOWLEDGEMENTS}

Core funding for Phases 1 and 2 of the CSHA was provided by the Seniors' Independence Research Program, through Health Canada's NHRDP. Funding for analysis of the caregiver component was provided by the Medical Research Council. Additional funding was provided by Pfizer Canada Inc. through the MRC/PMAC, NHRDP, by Bayer Inc., and by the B.C. Health Research Foundation. Core funding for Phase 3 was provided by the CIHR. Supplementary funding for the caregiver component was obtained from CIHR. Additional funding was provided by Merck-Frosst and by Jansen-Ortho. CSHA was coordinated through the University of Ottawa and Health Canada. Portions of these data were presented at the 17th World Congress of the International Association of Gerontology, Vancouver, 2001 and at the 43rd Annual Conference of the Australian Psychological Society, Hobart, 2008.

\section{REFERENCES}

[1] American Psychiatric Association (1987) Diagnostic and statistical manual of mental disorders. 3rd Edition Revised, American Psychiatric Association, Washington DC.

[2] Edelstein, B.A. and Segal, D.L. (2011) Assessment of emotional and personality disorders in older adults. In: Schaie, K.W. and Willis S.L., Eds., Handbook of the Psychology of Aging, 7th Edition, Academic Press, London, 339-352. doi:10.1016/B978-0-12-380882-0.00021-8

[3] Field, D. and Millsap, R.E. (1991) Personality in advanced old age: Continuity or change? Journal of Gerontology, 46, P299-P308. doi:10.1093/geronj/46.6.P299

[4] Costa Jr., P.T. and McCrae, R.R. (1988) Personality in adulthood: A six-year longitudinal study of self-reports and spouse ratings on the NEO personality inventory. Journal of Personality and Social Psychology, 54, 853863. doi:10.1037/0022-3514.54.5.853

[5] Conley, J.J. (1985) Longitudinal stability of personality traits: A multitrait-multimethod-multioccasion analysis. Journal of Personality and Social Psychology, 49, 12661282. doi:10.1037/0022-3514.49.5.1266

[6] Allemand, M., Zimprich, D. and Herzog, C. (2007) Crosssectional age differences and longitudinal age changes of personality in middle adulthood and old age. Journal of Personality, 75, 323-358. doi:10.1111/j.1467-6494.2006.00441.x

[7] Allemand, M., Zimprich, D. and Martin, M. (2008) Longterm correlated change in personality traits in old age. Psychology and Aging, 23, 545-557. doi: $10.1037 / \mathrm{a} 0013239$

[8] Small, B.J., Hertzog, C., Hultsch, D.F., et al. (2003) Stability and change in adult personality over 6 years: Findings from the victoria longitudinal study. Journal of Gerontology, 58B, P166. doi:10.1093/geronb/58.3.P166

[9] Donnellan, M.B. and Lucas, R.E. (2008) Age differences in the big five across the life span: Evidence from two national samples. Psychology and Aging, 23, 558-566. doi: $10.1037 / \mathrm{a} 0012897$

[10] Nilsson, L.V. and Persson, G. (1984) Personality changes in the aged: A longitudinal study of psychogenic needs with the CMPS. Acta Psychiatrica Scandinavica, 69, 182189. doi:10.1111/j.1600-0447.1984.tb02485.x

[11] Starratt, C. and Peterson, L. (1997) Personality and normal aging. In: Nussbaum, P.D., Ed., Handbook of Neuropsychology and Aging, Plenum, New York, 15-31.

[12] Widiger, T.A. and Seidlitz, L. (2002) Personality, psychopathology, and aging. Journal of Research in Personality, 36, 335-362. doi:10.1016/S0092-6566(02)00013-2

[13] Barnes, L.L., Mendes de Leon, C.F., Bienias, J.L., et al. (2009) Hostility and change in cognitive function over time in older blacks and whites. Psychosomatic Medicine, 71, 652-658. doi:10.1097/PSY.0b013e3181a651b3

[14] Wilson, R.S., Evans, D.A., Bienias, J.L., et al. (2003) Proneness to psychological distress is associated with risk of Alzheimer's disease. Neurology, 61, 1479-1485. doi:10.1212/01.WNL.0000096167.56734.59

[15] Wilson, R.S., Fleischman, D.A., Myers, R.A., et al. (2004) Premorbid proneness to distress and episodic memory impairment in Alzheimer's disease. Journal of Neurology, 
Neurosurgery and Psychiatry, 75, 191-195.

[16] Szwabo, P.A. and Boesch, K.R. (1993) Impact of personality and personality disorders in the elderly. In: Szwabo, P.A. and Greenberg, G.T., Eds., Problem Behaviors in Long-Term Care: Recognition, Diagnosis and Treatment, Springer, New York, 59-69.

[17] Hagberg, B., Samuelsson, G., Lindberg, B., et al. (1991) Stability and change of personality in old age and its relation to survival. Journal of Gerontology, 46, P285-P291. doi:10.1093/geronj/46.6.P285

[18] Mroczek, D.K. and Spiro, A.I. (2007) Personality change influences mortality in older men. Psychological Science, 18, 371-376. doi:10.1111/j.1467-9280.2007.01907.x

[19] Danner, D.D., Snowdon, D.A. and Friesen, W.V. (2001) Positive emotions in early life and longevity: Findings from the nun study. Journal of Personality and Social Psychology, 80, 804-813. doi:10.1037/0022-3514.80.5.804

[20] Wilson, R.S., Bienias, J.L., Mendes de Leon, C.F., et al. (2003) Negative affect and mortality in older persons. American Journal of Epidemiology, 158, 827-835. doi:10.1093/aje/kwg224

[21] Stuss, D.T., Gow, C.A. and Hetherington, C.R. (1992) No longer gage: Frontal lobe dysfunction and emotional changes. Journal of Consulting and Clinical Psychology, 60, 349359. doi:10.1037/0022-006X.60.3.349

[22] Gregory, C.A. and Hodges, J.R. (1996) Clinical features of frontal lobe dementia in comparison to Alzheimer's disease. Journal of Neural Transmission, Supplementum, 47, 103-123. doi:10.1007/978-3-7091-6892-9 6

[23] Hooten, W.M. and Lyketsos C.G. (1996) Frontotemporal dementia: A clinicopathological review of four postmortem studies. Journal of Neuropsychiatry and Clinical Neurosciences, 8, 10-19.

[24] Kipps, C.M., Knibb, J.A. and Hodges, J.R. (2007) Clinical presentations of frontotemporal dementia. In: Hodges, J.R., Ed., Frontotemporal Dementia Syndromes, Cambridge University Press, Cambridge, 38-79.

[25] Wilson, R.S., Schneider, J.A., Arnold, S.E., et al. (2007) Conscientiousness and the incidence of Alzheimer disease and mild cognitive impairment. Archives of General Psychiatry, 64, 1204-1212. doi:10.1001/archpsyc.64.10.1204

[26] Aitken, L., Simpson, S. and Burns, A. (1999) Personality change in dementia. International Psychogeriatrics, 11, 263-271. doi:10.1017/S1041610299005827

[27] Helson, R., Jones, C. and Kwan, V.S.Y. (2002) Personality change over 40 years of adulthood: Hierarchical linear modelling analyses of two longitudinal samples. Journal of Personality and Social Psychology, 83, 752766. doi:10.1037/0022-3514.83.3.752

[28] Crowe, M., Andel, R., Pedersen, N.L., Fratiglioni, L., et al. (2007) Personality and risk of cognitive impairment 25 years later. Psychology and Aging, 21, 573-580. doi:10.1037/0882-7974.21.3.573

[29] Skoog, I., Lernfelt, B., Landahl, S., et al. (1996) 15-year longitudinal study of blood pressure and dementia. Lancet, 347, 1141-1145.

\section{doi:10.1016/S0140-6736(96)90608-X}

[30] Kolanowski, A.M. and Whall, A.L. (1996) Life-span perspective of personality in dementia. Journal of Nursing Scholarship, 28, 315-320. doi:10.1111/j.1547-5069.1996.tb00380.x

[31] Rubin, E.H., Morris, J.C. and Berg, L. (1987) The progression of personality changes in senile dementia of the Alzheimer's type. Journal of the American Geriatrics Society, 35, 721-725.

[32] Petry, S., Cummings, J.L., Hill, M.A., et al. (1988) Personality alterations in dementia of the Alzheimer type. Archives of Neurology, 45, 1187-1190.

doi:10.1001/archneur.1988.00520350025009

[33] Talassi, E., Cipriani, G., Bianchetti, A., et al. (2007) Personality changes in Alzheimer's disease. Aging and Mental Health, 11, 526-531. doi:10.1080/13607860601086603

[34] Bozzola, F.G., Gorelick, P.B. and Freels, S. (1992) Personality changes in Alzheimer's disease. Archives of Neurology, 49, 297-300. doi:10.1001/archneur.1992.00530270117027

[35] Jacomb, P.A. and Jorm, A.F. (1996) Personality change in dementia of the Alzheimer type. International Journal of Geriatric Psychiatry, 11, 201-207. doi:10.1002/(SICI)1099-1166(199603)11:3<201::AID-G PS299>3.0.CO;2-N

[36] Jorm, A.F. and Jacomb, P.A. (1989) The Informant questionnaire on cognitive decline in the elderly (IQCODE): Sociodemographic correlates, reliability, validity and some norms. Psychological Medicine, 19, 1015-1022.

[37] Jorm, A.F. (2004) The informant questionnaire on cognitive decline in the elderly (IQCODE): A review. International Psychogeriatrics, 16, 1-19. doi:10.1017/S1041610204000390

[38] Canadian Study of Health and Aging Working Group (1994) Canadian study of health and aging: Study methods and prevalence of dementia. Canadian Medical Association Journal, 150, 899-913.

[39] Eastwood, R., Nobbs, H., Lindsay, J., et al. (1992) Canadian study of health and aging. Dementia, 3, 209-212.

[40] Graham, J.E., Rockwood, K., Beattie, B.L., et al. (1996) Standardization of the diagnosis of dementia in the Canadian study of health and aging. Neuroepidemiology, 15, 246-256. doi:10.1159/000109914

[41] Teng, E.L. and Chui, H.C. (1987) The modified minimental state (3-MS) examination. Journal of Clinical Psychiatry, 48, 314-318.

[42] McKhann, G., Drachman, D., Folstein, M., et al. (1984) Clinical diagnosis of Alzheimer's disease: Report of the NINCDS-ARDRA work group under the auspices of department of health and human services task force on Alzheimer's Disease. Neurology, 34, 939-943. doi:10.1212/WNL.34.7.939

[43] Roth, M., Huppert, F.A., Tym, E., et al. (1988) CAMDEX: The Cambridge examination for mental disorders of the elderly. Cambridge University Press, Cambridge.

[44] Welleford, E.A., Harkins, S.W. and Taylor, J.R. (1995) 
Personality change in dementia of the Alzheimer's type: Relations to caregiver personality and burden. Experimental Aging Research, 21, 295-314. doi:10.1080/03610739508253986

[45] Williams, R., Briggs, R. and Coleman, P. (1995) Carerrated personality changes associated with senile dementia. International Journal of Geriatric Psychiatry, 10, 231236. doi:10.1002/gps.930100309

[46] Cosentino, S. and Stern, Y. (2005) Metacognitive theory and assessment in dementia: Do we recognize our areas of weakness? Journal of the International Neuropsychological Society, 11, 910-919. doi:10.1017/S1355617705050964

[47] Verhey, F.R.J., Rudolf, W.H.M., Rozendaal, N., et al. (1995) Depression, insight, and personality changes in Alzheimer's disease and vascular dementia. Journal of Geriatric Psychiatry and Neurology, 8, 23-27.

[48] Siegler, I.C., Dawson, D.V. and Welsh, K.A. (1994) Caregiver ratings of personality change in Alzheimer's disease patients: A replication. Psychology and Aging, 9, 464-466. doi:10.1037/0882-7974.9.3.464

[49] Strauss, M.E. and Pasupathi, M. (1994) Primary caregivers' descriptions of Alzheimer patients' personality traits: Temporal stability and sensitivity to change. Alzheimer Disease and Associated Disorders, 8, 166-176. doi:10.1097/00002093-199408030-00003

[50] Jacomb, P., Jorm, A., Christensen, H., et al. (1994) Personality changes in normal and cognitively impaired elderly: Informant reports in a community sample. International
Journal of Geriatric Psychiatry, 9, 313-320. doi:10.1002/gps.930090408

[51] Strauss, M.E., Stuckey, J.C., Pasupathi, M., et al. (1997) Accuracy of retrospective descriptions of personality during the course of Alzheimer's disease. Journal of Clinical Geropsychology, 3, 93-99.

[52] Heinik, J., Keren, P., Vainer-Baenaiah, Z., et al. (1999) Agreement between spouses and children in descriptions of personality change in Alzheimer's disease. Israel Journal of Psychiatry and Related Sciences, 36, 88-94.

[53] Kurtz, J.E., Lee, P.A. and Sherker, J.L. (1999) Internal and temporal reliability estimates for informant ratings of personality using the NEO-PI-R and IAS. Assessment, 6, 103-113. doi:10.1177/107319119900600201

[54] Dawson, D.V., Welsh-Bohmer, K.A. and Siegler, I.C. (2000) Premorbid personality predicts level of rated personality change in patients with Alzheimer disease. Alzheimer Disease and Associated Disorders, 14, 11-19. doi:10.1097/00002093-200001000-00002

[55] Meins, W. and Dammast, J. (2000) Do personality traits predict the occurrence of Alzheimer's disease? International Journal of Geriatric Psychiatry, 15, 120-124. doi:10.1002/(SICI)1099-1166(200002)15:2<120::AID-G PS84>3.0.CO;2-7

[56] Smith-Gamble, V., Baiyewu, O., Perkins, A.J., et al. (2002) Informant reports of changes in personality predict dementia in a population-based study of elderly African Americans and Yoruba. American Journal of Geriatric Psychiatry, 10, 724-732. 